УДК 621.391

\title{
ТЕХНОЛОГИЯ ФОРМИРОВАНИЯ СУРРОГАТНЫХ ДАННЫХ С ИСПОЛЬЗОВАНИЕМ МЕТОДА SSА ДЛЯ ПОВЫШЕНИЯ ЭФФЕКТИВНОСТИ СПЕКТРАЛЬНОГО АНАЛИЗА СИГНАЛОВ
}

\author{
КОСТЕНКО П. Ю., ВАСИЛИШИН В. И.
}

Харьковский университет Воздушных Сил, Украина, Харьков, 61023, ул. Сумская 77/79

\begin{abstract}
Аннотация. Рассмотрена задача повышения эффективности спектрального анализа сигналов, наблюдаемых на фоне шума, методом Root-MUSIC с использованием свободной от суррогатного шума технологии суррогатных данных, полученных применением метода сингулярного спектрального анализа SSA (Singular Spectra Analysis). Показана эффективность применения этой технологии в диапазоне малых и больших отношений сигнал-шум
\end{abstract}

Ключевые слова: суррогатные данные; суррогатный шум; сингулярный спектральный анализ; метод Root-MUSIC

\section{ВВЕДЕНИЕ}

Спектральному анализу сигналов, который включает решение задач определения числа гармонических компонент сигнала и оценивания их параметров по наблюдению в присутствии аддитивного белого гауссового шума, посвящено много работ, в которых отмечается, что его эффективность существенно зависит от отношения сигнал-шум (ОСШ), числа наблюдений и выбранного метода анализа [1].

Среди современных методов спектрального анализа особое место занимают так называемые собственноструктурные (СС) методы, часто применяемые при обработке пространственно-временных сигналов [1-3]. Эти методы основаны на использовании информации, которая содержится в собственных векторах (CB) и собственных значениях (C3) корреляционной матрицы (КМ) наблюдений.

В антенных решетках (АР) для уменьшения влияния шума на оценку КМ наблюдения если возможно используют многократную регистрацию поля от источников сигнала и последующую обработку ансамбля наблюдений для улучшения оценки КМ. Если компоненты сигнала коррелированы, выполняют их декорреляцию сглаживанием оценок КМ [1], полученным по неполной выборке данных с части элементов АР.

Однако, на практике нередко встречаются ситуации, когда мощность сигнала меньше мощности шума, а получить большой ансамбль наблюдений не представляется возможным [1-4]. Кроме того, для обработки доступно единственное наблюдение, длина которого недостаточна (малая выборка), чтобы воспользоваться асимптотическими свойствами статистики его распределения.

Следует отметить, что декорреляция наблюдений (сигналов) с использованием пространственного сглаживания КМ приводит к недопустимому снижению разрешающей спо- 